(C2007 IEEE. Personal use of this material is permitted. However, permission to reprint/republish this material for advertising or promotional purposes or for creating new collective works for resale or redistribution to servers or lists, or to reuse any copyrighted component of this work in other works must be obtained from the IEEE. 


\title{
Induction Motor Load Generator System Using Direct Torque Control Method
}

\author{
Iman Mazhari, Abolfazl Vahedi and M.A.S. Masoum
}

\begin{abstract}
Implementation of complicated tests for electrical machines usually demands special experimental setups and equipments. Getting to this target, electrical machine test benches are designed and constructed. In this paper, a direct torque controlled (DTC) load generator based on space vector modulation is proposed. To realize system performance with DTC method, classical DTC has been analyzed and is used for modelling the dynamometer. The performance of proposed dynamometer is investigated by simulating different parts of the system in SIMULINK/MATLAB environment and results are presented for several industrial load profiles.
\end{abstract}

Index Terms-- Induction motor, direct torque control, load generator system, industrial loads Nomenclature

\section{INTRODUCTION}

A dvanced industrial variable speed drive systems are complex combination of an electrical machine, a power electronic device and a digital microprocessor system, executing a control algorithm [1-9]. Such devices can be used in applications where high precision servo performance is desired. For this purpose, test of the total drive system, under controlled conditions, in the laboratory for desired industrial load profiles is useful. Test bench is a proper device for achieving this target. It is composed of three sections; dynamometer and its control unit, data processing system and motor under test. Dynamometer is commonly used to produce appropriate mechanical load profile, because it is not always possible to test the electrical machine directly with actual load. Hence any electrical machine can be mounted in the place of the motor under test to determine its transient and steady state characteristics with a practical load. In classical dynamometer, the load is adjusted by altering the frictional drag or the electrical output torque of the generator or by varying the slip. In both cases, the load is passive and the machine can only be tested under steady state condition. In [9], dynamic load generator (dynamometer) is implemented using a DC motor which is based on the reference model control. In [5], dynamometer control is performed in a closed loop manner. Therefore, the motor and drive are integral components of the

I. Mazhari and A.Vahedi are with the Center of Excellence for Power Systems Operation \& Automation, Department of Electrical Engineering, Iran University of Science \& Technology, Narmak, Tehran, IRAN, 16846, (emails: iman_mazhari@ee.iust.ac.ir \& avahedi@iust.ac.ir).

Mohammad A.S. Masoum is with the Department of Electrical Engineering, Curtin University of Technology, Perth, WA6845, Australia (email:m.masoum@curtin.edu.au). closed loop control system and their torque characteristics must be measured under loading conditions which may not be possible in some applications. In [1], the dynamometer is simulated for an induction motor using the conventional vector control method. In [8], a 10hp induction motor is selected as the load generator and vector control approach is used to implement a test bench for hybrid cars.

In this paper, a new approach for simulation of the dynamometer is described and a direct torque controlled (DTC) load generator based on space vector modulation is proposed. To investigate the performance of the proposed method, precise models of different parts of the system are described in SIMULINK/MATLAB and some typical (static and dynamic) industrial loads are generated and imposed on the motor under test. Simulation results show that the static and dynamic characteristics of industrial linear and nonlinear loads can be modelled precisely for the motors and drives under test.

The outline of the paper is as follows: the principle of the direct torque control is presented in Section 2 and simulation results for a conventional method are presented. Section 3 discuses the static and dynamic characteristics of the mechanical load to produce any arbitrary load profile. It is assumed that torque characteristics of the arbitrary load versus speed is known and the user inputs the desired load characteristics by selecting polynomial and inertia coefficients. Section 4 is dedicated to the control of dynamometer. System modelling and simulation results are provided in Section 5.

\section{PRINCIPLES OF DTC}

In 1985, the idea of direct torque control (DTC) was introduced with bang-bang control that performs very well with on-off operation of the inverter semiconductor power devices. DTC of inverter fed induction motor is carried out by hysteresis control of magnitude stator flux and torque that selects one of the six non-zero and two zero inverter space vectors as shown in Fig.1. The electromechanical torque $T_{e m}$ produced by an induction motor is given by:

$T_{\text {em }}=\frac{3}{2} p \frac{L_{m}}{\sigma L_{S} L_{r}} \phi_{s} \times \phi_{r}$

Where $X$ indicates the vector product operator and $\sigma=1-L_{m} / L_{s}^{\prime} L_{r}$ is the total leakage coefficient. Because rotor time constant is larger than stator time constant, the rotor flux changes slowly compared with the stator flux; in fact the rotor flux can be assumed to be constant. Neglecting ohmic losses, 
stator voltage directly influences stator flux in accordance with the following equation:

$\frac{d \phi_{S}}{d t}=V_{s}$

$\Delta \phi_{S}=V_{S} \Delta t$

Figure 1 shows the possible dynamic locus of the stator flux and its different variations depending on the selected VSI states. The possible global locus is divided into six different sectors separated by discontinuous lines [3].

In accordance with Fig.1, general selections of voltage states are listed in Table 1. Note that for each sector, states $V_{k}$ and $V_{k+3}$ are not considered in the torque calculations since torque can not simultaneously increase (first 30 degrees) or decrease (second 30 degrees) at the same sector depending on the stator flux position.

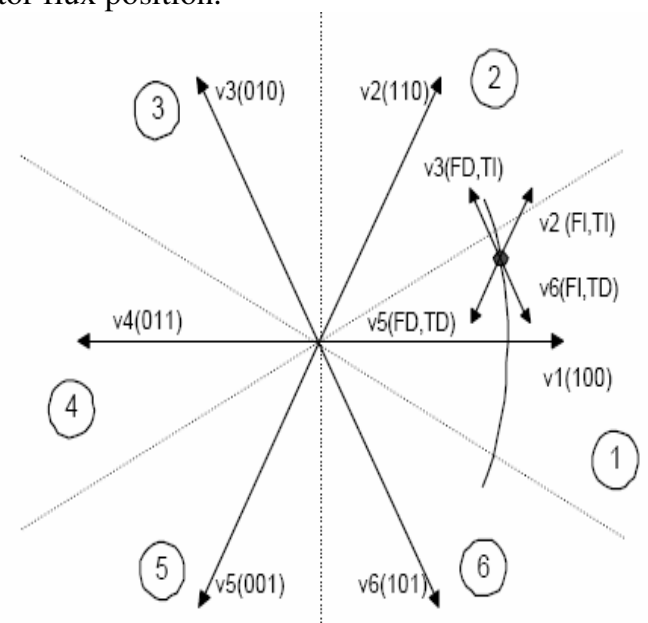

Fig 1. Stator flux vector locus and different possible switching voltage vectors (FD: flux decrease, FI: flux increase, TD: torque decrease, and TI: torque increase).

A possible schematic of direct torque control is shown in Figure 2. There are two different loops corresponding to the magnitudes of the stator flux and torque. The reference value for the flux stator modulus and the torque are compared with the actual values, and the resulting errors are fed into two-level and three-level hysteresis blocks. Outputs of hysteresis blocks with the position of the stator flux that can be in any of six sectors are used as inputs of the look up table.

TABLE I

GENERAL SELECTION TABLE FOR DIRECT TORQUE CONTROL (K IS THE SECTOR NUMBER).

\begin{tabular}{|c|c|c|}
\hline $\begin{array}{c}\text { Voltage } \\
\text { vector }\end{array}$ & Increase & Decrease \\
\hline Stator flux & $V_{k}, V_{k+1}, V_{k-1}$ & $V_{k+2}, V_{k-2}, V_{k+3}$ \\
\hline Torque & $V_{k+1}, V_{k+2}$ & $V_{k-1}, V_{k-2}$ \\
\hline
\end{tabular}

There are other methods for decreasing the output torque ripple that can be used in the control section of load generator system. $[3,4,6]$.

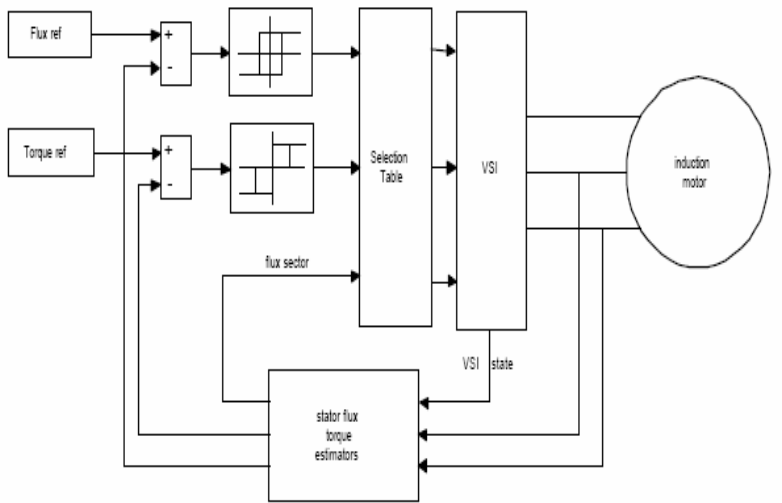

Fig 2. Block diagram of direct torque control (DTC)

\section{CHARACTERISTICS OF TYPICAL LOAD}

To generate the required load profile, the characteristic of the load must be known. To do this, torque characteristics of the load is divided into two sections corresponding to static and dynamic components:

$T_{\text {load }}=T_{d}+T_{s}$

Static component, presents the load torque for any steady state speed while static torque characteristics as stated by Eq.5 is a function of speed

$T_{S}=\sum_{n=-\infty}^{\infty} A_{n} \omega_{m}^{n}$

where $T_{S}$ is the static torque of the load in Nm, $\omega_{m}$ is angular speed of the motor in $\mathrm{rad} / \mathrm{sec}$ and $A_{n}$ are constants that are chosen manually according to the load characteristics. The dynamic characteristic of the load shows load torque in the accelerating and decelerating durations. The following equation gives dynamic torque of a rotational body.

$T_{l d}=J_{l} \frac{d \omega}{d t}$

Angular acceleration value in accelerating duration is positive and this dynamic torque is added to the load torque. In the deceleration duration, this term is negative and the resultant dynamic torque is added to the dynamometer torque and under steady state conditions, this term of load torque is zero. The general equation is demonstrated as follows:

$T_{\text {load }}=T_{l d}+T_{l s}=J_{l} \frac{d \omega_{m}}{d t}+\sum_{n=-\infty}^{\infty} A_{n} \omega_{m}^{n}$

As shown in Fig.1, if the electric drive is rotating a mechanical load, we have:

$T_{\text {em }}-T_{\text {load }}=J_{m} \frac{d \omega}{d t}+D_{m} \omega_{m}$

$T_{\text {load }}=J_{l} \frac{d \omega_{m}}{d t}+\sum_{n=-\infty}^{\infty} A_{n} \omega_{m}^{n}+D_{l} \omega_{m}$

Substituting Eq.9 in Eq.8:

$T_{e m}=J_{m} \frac{d \omega_{m}}{d t}+D_{m} \omega_{m}+J_{l} \frac{d \omega_{m}}{d t}+\sum_{n=-\infty}^{\infty} A_{n} \omega_{m}^{n}+D_{l} \omega_{m}$ 
$T_{e m}=J_{T} \frac{d \omega_{m}}{d t}+\sum_{n=-\infty}^{\infty} A_{n} \omega_{m}^{n}$

where $D_{l} \omega_{m}$ and $D_{m} \omega_{m}$ can be combined in $\sum_{n=-\infty}^{\infty} A_{n} \omega_{m}^{n}$.

\section{CONTROLLING THE DYNAMOMETER}

In reality, dynamometer is substituted with the real load in an electrical test bench. Therefore, it should be capable of producing (static and dynamic) torque speed characteristics of different loads. Figure 3 shows the final synthesized system with a motor under test (MUT) and the load generator motor (LGM). In this system, the LGM motor produces the desired load with DTC method and forces the MUT motor to perform with this condition.

Based on Eq.9, the arbitrary mechanical load can be expressed as:

$$
\begin{aligned}
& T_{\text {load }}^{*}=A_{0}+A_{1} \omega_{m}+A_{2} \omega_{m}^{2}+A_{3} \omega_{m}^{3}+\ldots \ldots \\
& +J_{\text {em }} \frac{d \omega_{m}}{d t}+D_{\text {em }} \omega_{m}
\end{aligned}
$$

where, $A_{0}, A_{l}, A_{2}, \ldots . . A_{n}$ are speed constants, $J_{e m}$ is the moment of inertia that must be generated by the dynamometer, and $\omega_{m}$ is the measured angular velocity (in $\mathrm{rad} / \mathrm{sec})$.

\section{MODELLING AND SIMULATION}

For precise realization and easy comparison between different states with DTC, the desired load profile is selected and is used as the input of the load generator motor (LGM). It should be noted that LGM should work in the generator region. Therefore, the rectifier should have the ability to return the energy to the power grid. This will considerably increase the computing time especially for applications requiring converter simulation for long durations. Another alternative to activate the energy revert is using an ideal DC power supply instead of the DC link voltage. For understanding the procedure of energy revert, the voltage oriented controlled PWM is simulated in Figs. 4 and 6 and the results are shown in Fig.6.

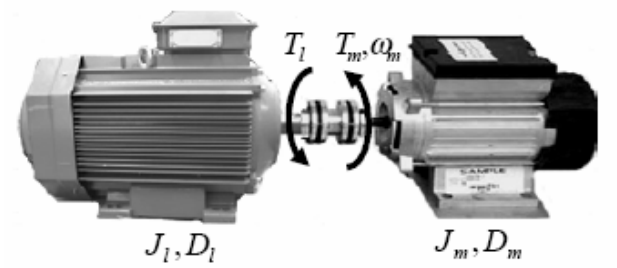

Fig 3 Motor under test (MUT) and the load generator motor (LGM) system.

In this example, it is assumed that the rectifier creates the DC voltage to $500 \mathrm{~V}$ and it's connected to the fixed load. At $\mathrm{t}=0.2$ second, the DC voltage in opposite side is connected to the load and so the direction of the current is reversed. With the selection of a proper control method, the current returns to the power grid. $\lambda_{\text {ref }}=\frac{E_{\text {emf }}}{4.44 f}=\frac{380 / \sqrt{2}}{4.44(50)}=1.2 \mathrm{Nwb}$.

TABLE II

NOMINAL PARAMETER VALUES FOR THE 4HP MOTOR

\begin{tabular}{|l|c|c|c|c|c|}
\hline $\begin{array}{c}\mathrm{V}_{\text {line }} \\
{[\mathrm{V}]}\end{array}$ & $\begin{array}{c}\mathrm{R}_{\mathrm{s}} \\
{[\Omega]}\end{array}$ & $\begin{array}{c}\mathrm{R}_{\mathrm{r}}^{\prime} \\
{[\Omega]}\end{array}$ & $\begin{array}{c}\mathrm{x}_{\mathrm{ls}}=\mathrm{x}_{\mathrm{lr}}^{\prime} \\
{[\Omega]}\end{array}$ & $\begin{array}{c}\mathrm{x}_{\mathrm{m}} \\
{[\Omega]}\end{array}$ & $J$ \\
\hline 380 & 8.28 & 6.16 & 9.92 & 244.23 & 0.02 \\
\hline
\end{tabular}

After designing the proper PWM, the industrial load profile should be selected and is exerted to the load generator motor. In this stage, the $4 \mathrm{hp}$ motor with the nominal values in Table. 2 is selected for both load generator motor (LGM) and motor under test (MUT). The nominal torque of the motor is 19.8NM. Simulation of final load generator system is shown in Fig.5.

It should be noted that the switching frequency of the IGBT's must be in the working frequency that is described in the datasheet. Therefore, a maximum frequency of $18 \mathrm{kHz}$ has been selected which is in the available range.

For the simulation, the reference flux is needed which can be calculated using Eq.13. Simulation results for " $T_{\text {ref }}=-10 \mathrm{NM}^{\prime} \quad, \quad " T_{\text {ref }}=-0.4 / 3 \omega_{\text {final }} \mathrm{Nm}^{\prime} \quad$ and $" T_{\text {ref }}=-\left(5+5 \sin (120 \pi t)+10^{-4} \omega_{\text {final }}^{2}\right) \mathrm{Nm}$ " are shown in Figs. 7-8, Figs. 9-10 and Figs. 11-12, respectively.

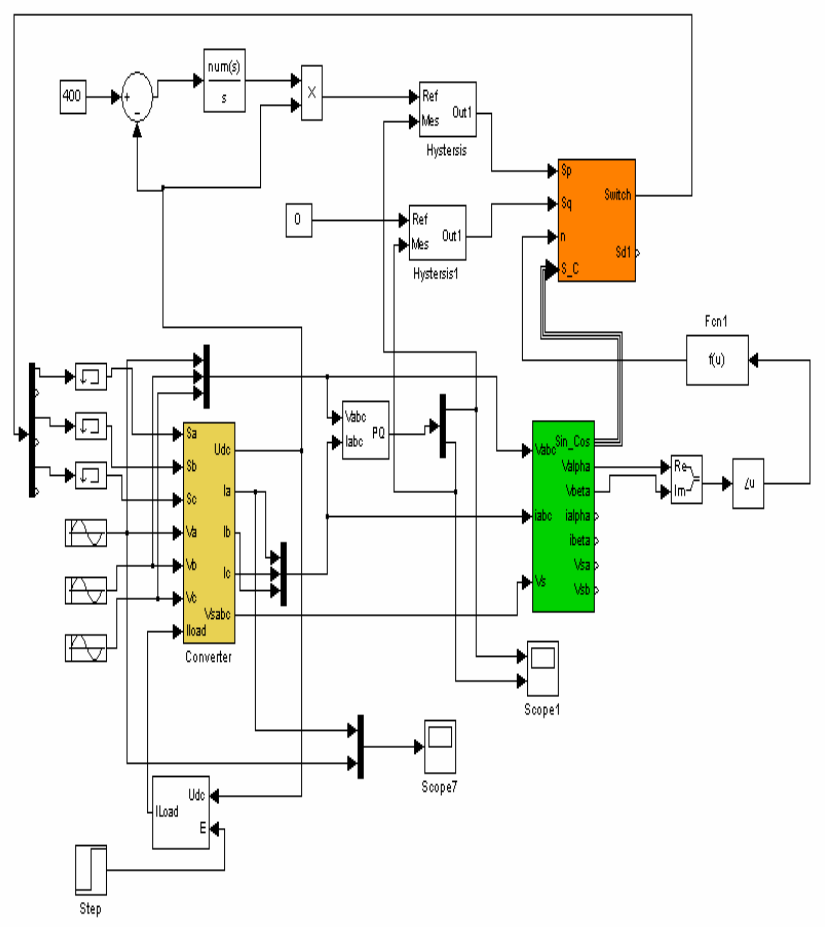

Fig 4. Simulation of VOC PWM 


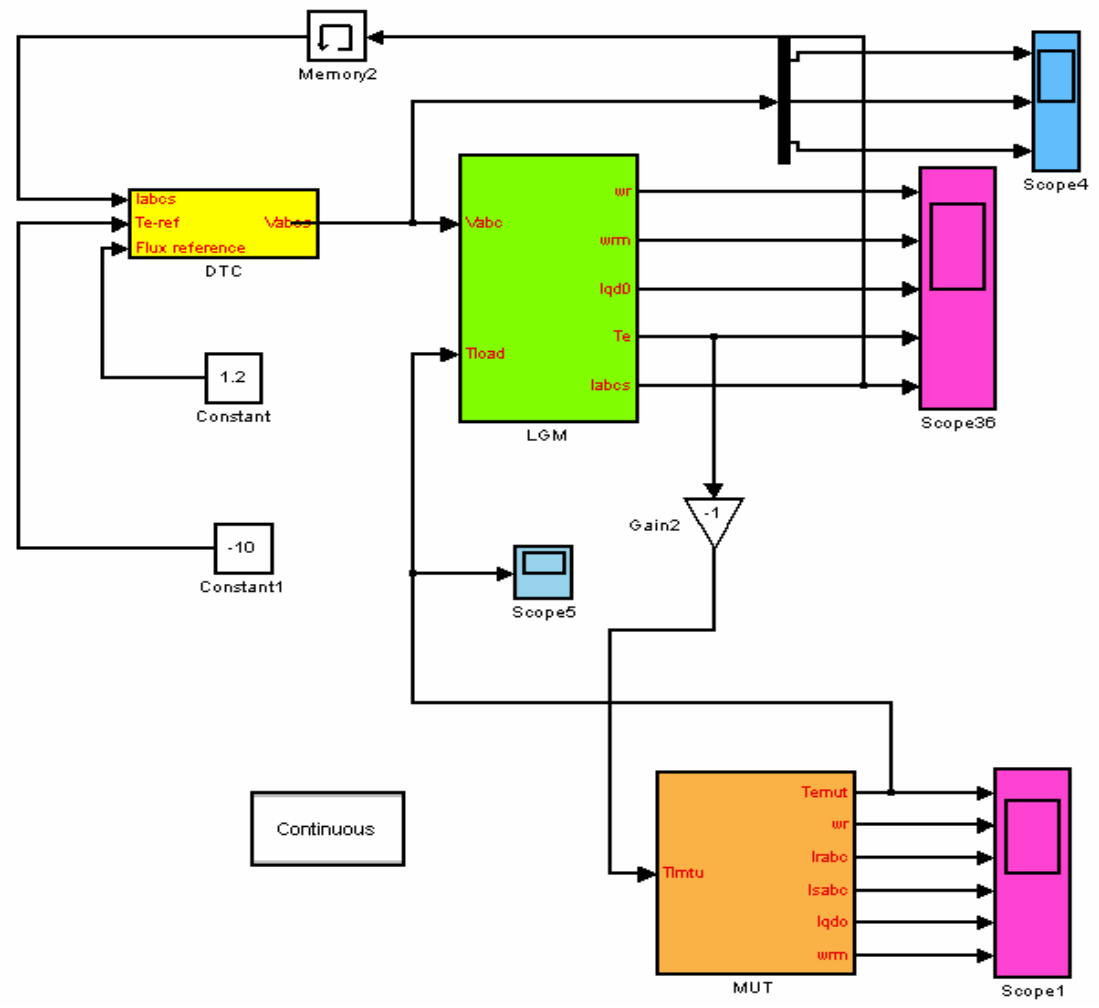

Fig 5. Simulation of the load generator system

All simulated conditions show fine torque tracking characteristics. However, in the load generator system, the mean of the LGM output torque is important, because the electromechanical torque of MUT is considered and the performance of the MUT is under the argument. The output torque of MUT is roughly constant with varying ripple component of torque of LGM.

The simulation results for $T_{r e f}=-10 N M$ by DTC with conventional switch table is shown in Fig.11 and Fig.12. By using the conventional switch table, the torque ripple is acceptable with fine accuracy of output torque (e.g., about $95 \%$ of the nominal value $(19.8 \mathrm{NM})$ ).

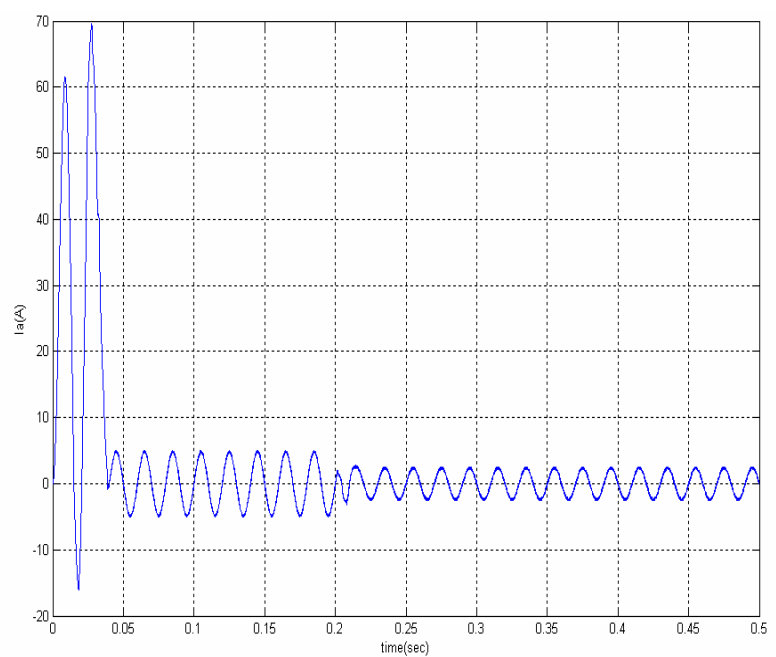

Fig 6. Output current of PWM in generator and motor regions
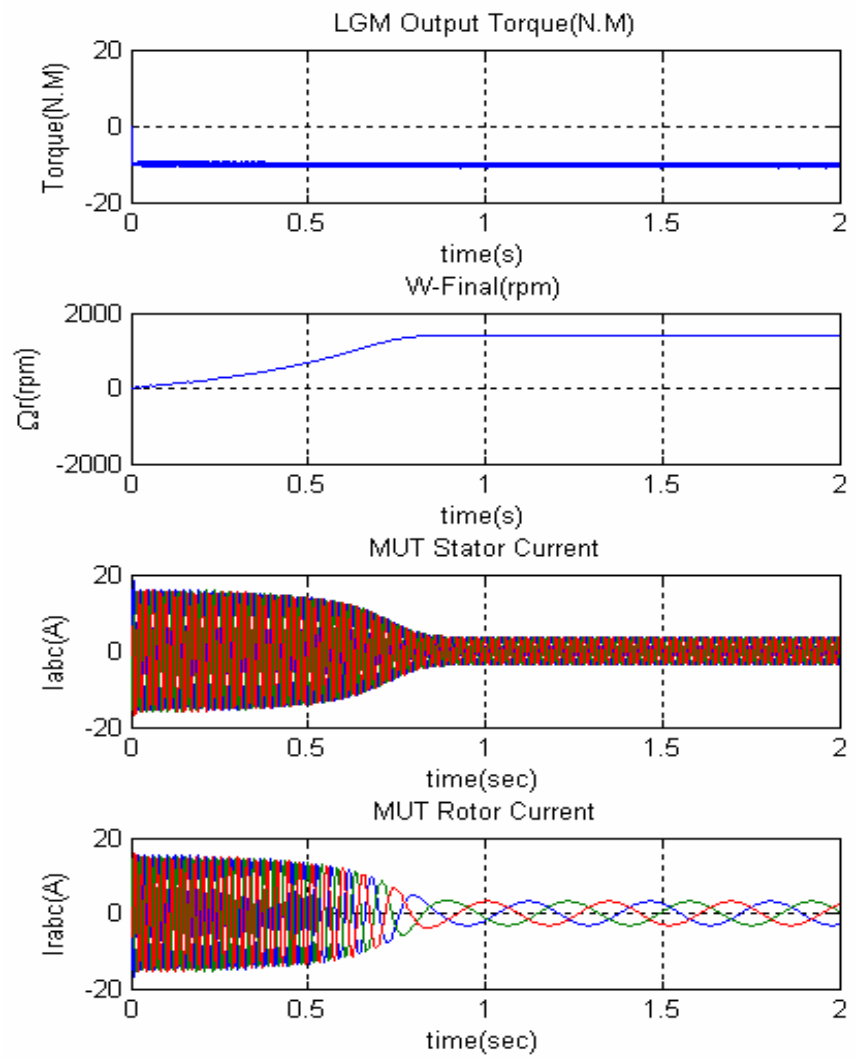

Fig 7 Simulation results for $T_{\text {ref }}=-10 N M$ by conventional DTC; (a) output torque of LGM, (b) final speed of the system, (c) MUT stator current, (d) MUT rotor current. 


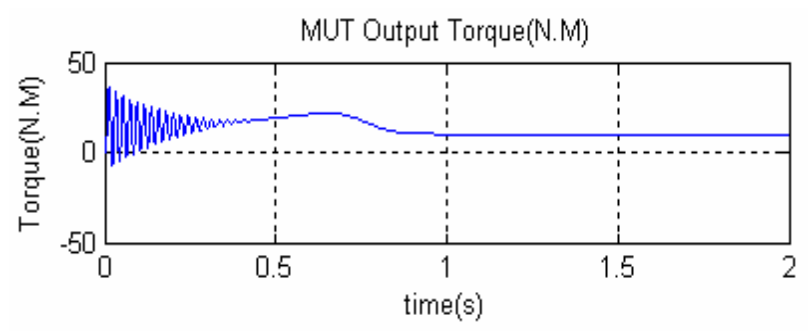

LGM Stator Current

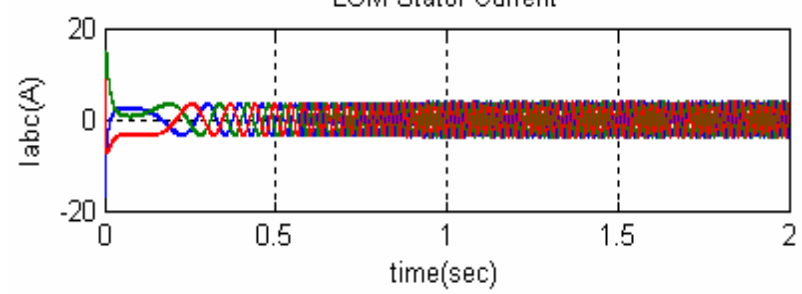

LGM Rotor Current

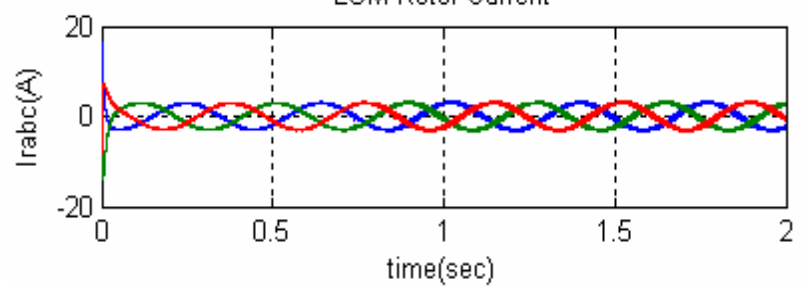

Figure 8 . Simulation results for $T_{r e f}=-10 N M$ by conventional DTC; (a) output torque of MUT, (b) LGM stator current, (c) LGM rotor current.
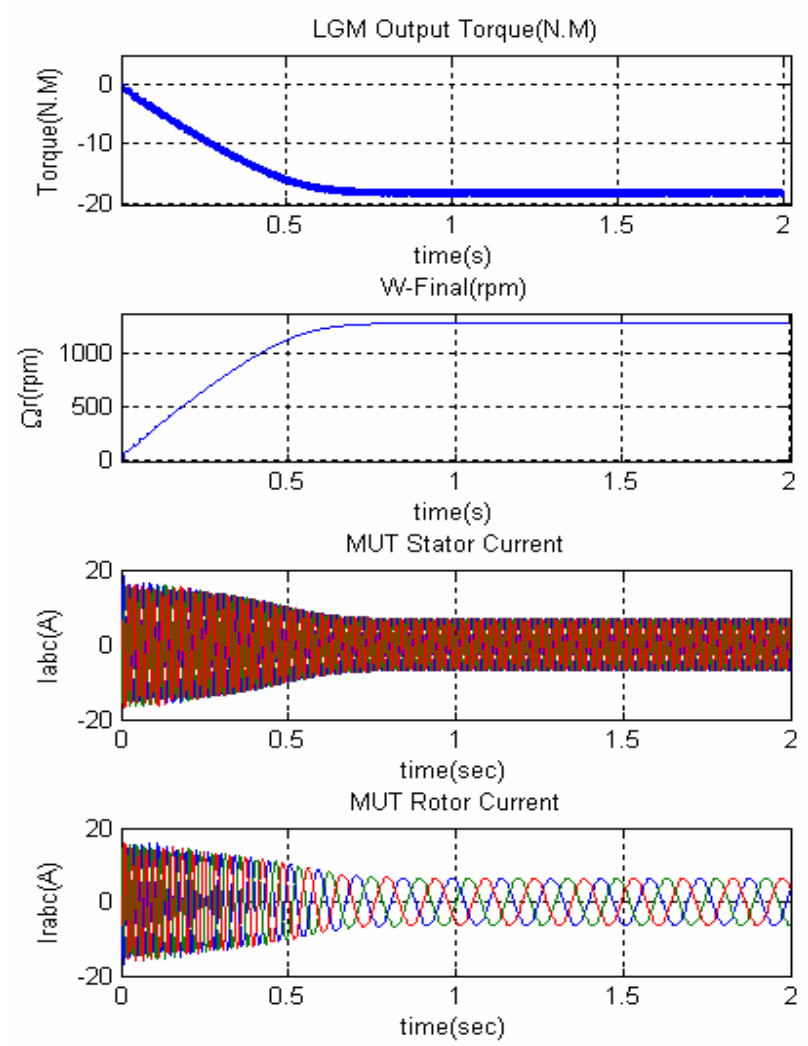

Fig 9. Simulation results by conventional DTC for $T_{\text {ref }}=-0.4 / 3 \omega_{\text {final }} \mathrm{Nm}$; (a) output torque of LGM, (b) final speed of the system (c) MUT stator current, (d) MUT rotor current.
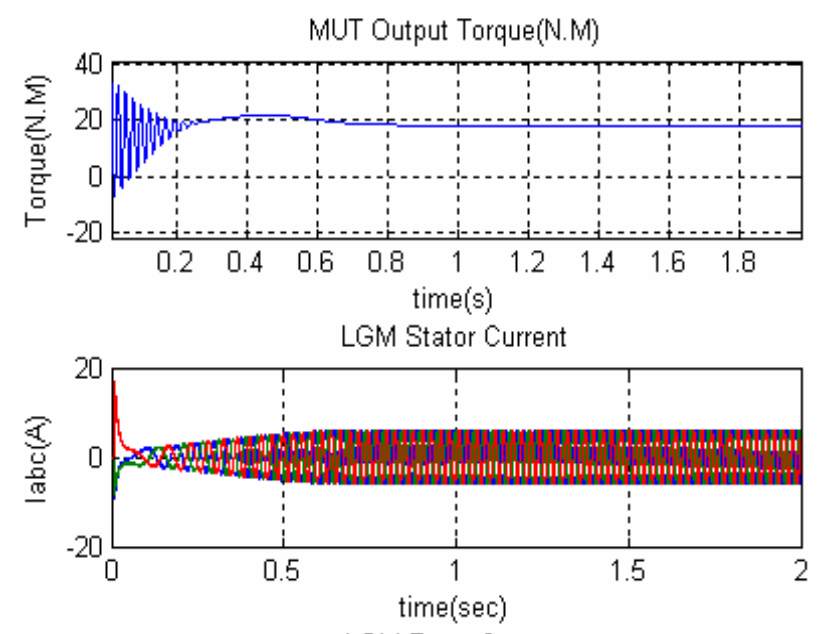

LGM Rotor Current

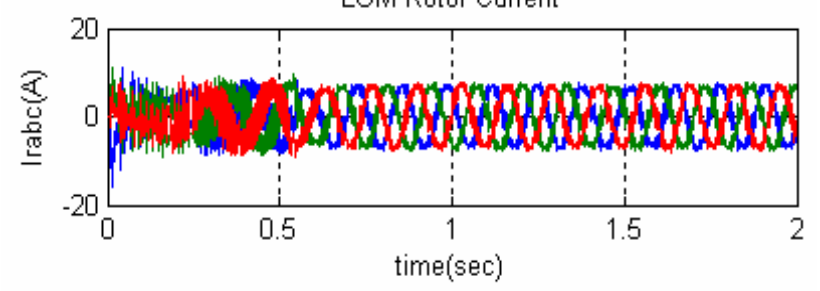

Figure 10. Simulation results by conventional DTC for $T_{\text {ref }}=-0.4 / 3 \omega_{\text {final }} \mathrm{Nm}$; (a) output torque of MUT, (b) LGM stator current, (c) LGM rotor current.
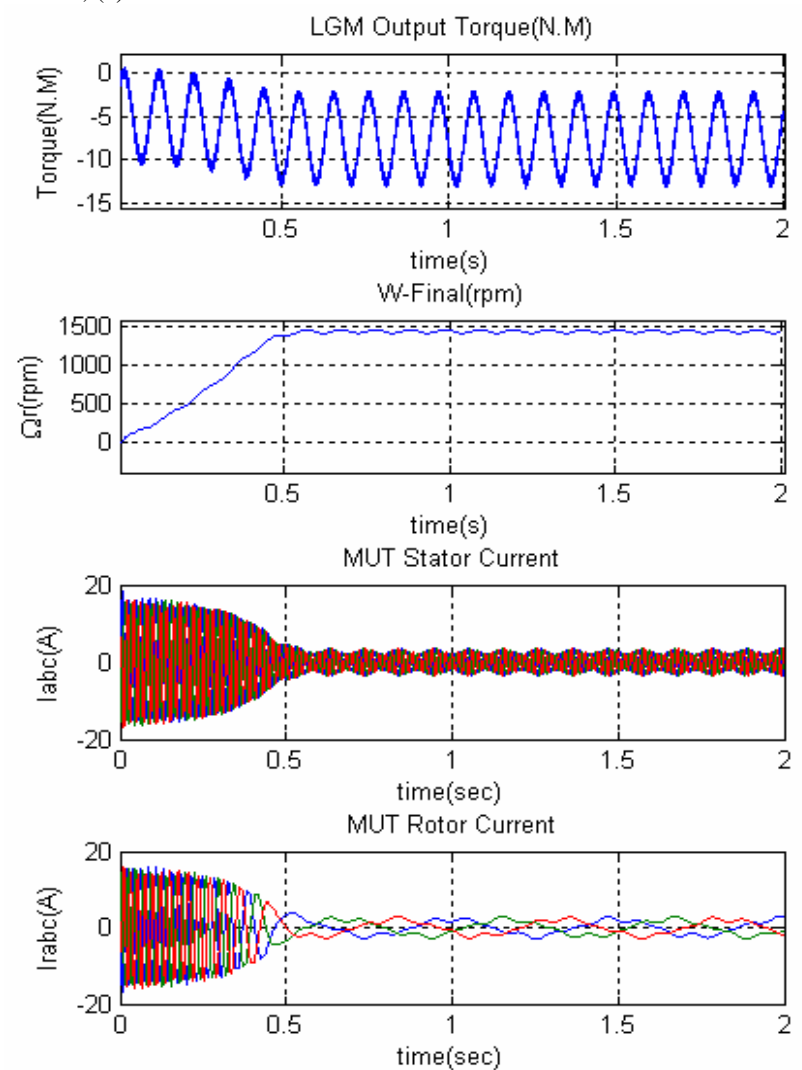

Figure 11 . Simulation results by conventional DTC for $T_{\text {ref }}=-\left(5+5 \sin (120 \pi t)+10^{-4} \omega_{\text {final }}^{2}\right) \mathrm{Nm}$; (a) output torque of LGM, (b) final speed of the system, (c) MUT stator current, (d) MUT rotor current. 


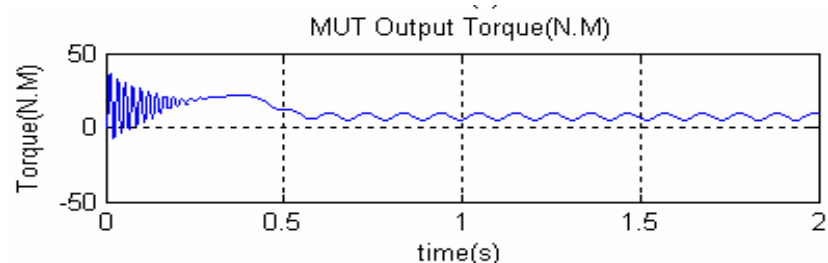

LGM Stator Current

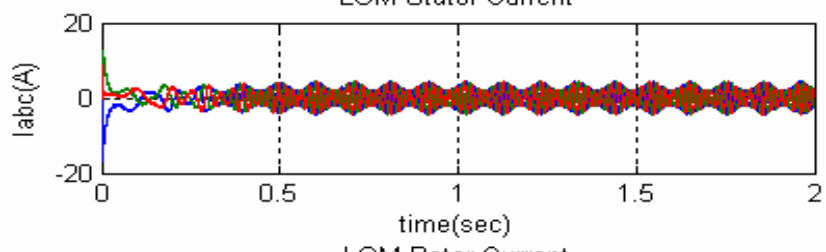

LGM Rotor Current

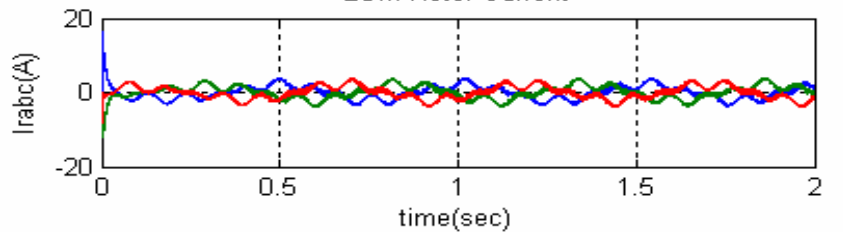

Figure 12. Simulation results by conventional DTC for $T_{\text {ref }}=-\left(5+5 \sin (120 \pi t)+10^{-4} \omega_{\text {final }}^{2}\right) \mathrm{Nm}$; (a) Output torque of MUT, (b) LGM stator current, (c) LGM rotor current.

\section{CONCLUSIONS}

A new method for configuration of the load generator system with induction motor has been introduced. For controlling the load generator motor, it should operate in the generator region which is possible by using a rectifier with the capability of reverting the energy to the power grid. A proper controlled PWM that can supply the power grid in the generator region has been simulated in this paper but it's too slow for using in load generator system. For this reason, an ideal DC power supply can be replaced with the rectifier. The proposed method follows the reference torque precisely and the time of the response and the starting current of the load generator motor have been significantly decreased. Furthermore, the proposed configuration is simpler, requires less simulation time and had higher efficiency, as compared to the conventional approaches. Different load profiles have been analyzed and the simulation results have been compared. Accuracy of the torque tracking in conventional DTC has been achieved to $95 \%$. Some advantages such as rapid response, less complexity, less driving current and precise accuracy has concluded in the mentioned method for using in test bench of electrical machines.

\section{REFERENCES}

[1] H.Azizi , A.Vahedi, " Dynamic and static load generator Based on Induction Motor Torque Tracking Control Method" ICEPOQ06, April2006.

[2] P.Vas, "Sensoreless Vector and Direct Torque Control", Oxford University Press, 1998.

[3] G.S. Buja and M. Kazmierkowski "Review of Direct Torque Control Methods for Voltage Source Inverter-fed Induction Motors". IEEE, 2003.

[4] G.S. Buja and M. Kazmierkowski. "Direct Torque Control of PWM Inverter-fed AC Motor- A Survey" IEEE Trans on Industrial Electronics, vol.51, no.4, August 2004.
[5] [5] E.R. Collins Jr. ,Y. Huang, "A Programmable Dynamometer for Testing Rotating Machinery Using a Three Induction Machine" IEEE Transaction on Energy Conversion, vol.9, no.3, pages: 521-527, Sep 1994..

[6] X. Wei, D. Chen and C. Zhao, "Minimization of Torque Ripple of Direct-Torque Controlled Induction Machines by Improved Discrete Space Vector Modulation”, Electric Power Systems Research 72, pages: 103-112, 2004.

[7] A.A. Pujol, "Improvements in Direct Torque Control of Induction Motors" Edicions UPC, Universitat Politècnica de Catalunya, 2000.

[8] R.M. Schupbach and J.C. Balda, "A Versatile Laboratory Test Bench for Developing Powertrains of Electrical Vehicles”, IEEE, Vehicular Technology Conference, vol.3, Sept. 2002.

[9] P.M, Cusack, "Testing of Large Motors to API 542 and 546 Standards", IEEE Transaction on Industrial Applications, vol.29, no.2, pages: 427434, March/April, 1993.

\section{BIOGRAPHIES}

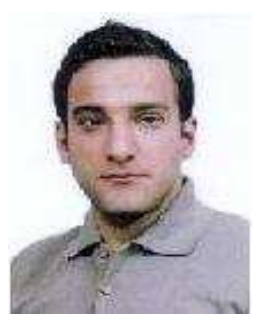

Iman Mazhari was born in Tehran on July18, 1982. He received the B.S degree in Electronic Engineering \& M.S Degree in Electrical Engineering from Iran University of Science \& Technology in 2004 and 2007 respectively.

His research interests include variable speed drives, FACTs devices, motor control, DSP Microcontrollers, Power electronics and automotives electronics. He has contributed in some projects in the field of Dynamometer and test bench for different kinds of electrical machines with several methods in Center of Excellence for Power Systems Operation \& Automation, Electrical Engineering department of Iran University of Science \& Technology.

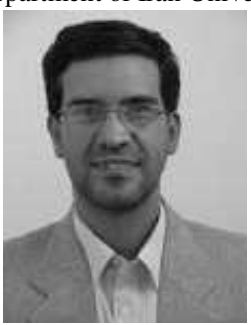

Abolfazl Vahedi received his B.S, M.S and Ph.D in 1989, 1992 and 1996 from Ferdowsi Mashhad University, Institut nationale polytechnique de Lorraine (INPL-France) and INPL all in electrical engineering respectively. $\mathrm{He}$ is Associate Professor in Department of Electrical Engineering of Iran University of Science \& Technology. He has directed several projects in the area of electrical machines and drives. His research interests are mainly design, implementation and optimization of electric machines and drives. He is a member of IEE, SEE.

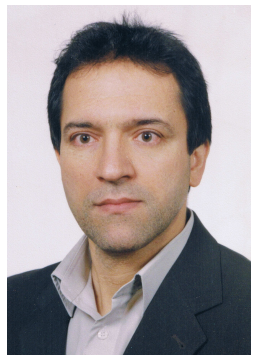

Mohammad A.S. Masoum (SM' 05) received his B.S., M.S. and Ph.D. degrees in Electrical and Computer Engineering in 1983, 1985, and 1991, respectively, from the University of Colorado at Boulder, USA. Currently, he is a Faculty Member at the Electrical and Computer Engineering Department, Curtin University of Technology, Perth, Australia. Dr Masoum is a senior member of IEEE. 